\title{
RISK FACTORS OF PULMONARY TUBERCULOSIS AMONG DIABETES MELLITUS PATIENTS: A CASE-CONTROL STUDY IN DR. KARIADI GENERAL HOSPITAL, SEMARANG, INDONESIA
}

\author{
Arulita Ika Fibriana1 ${ }^{1}$, Mahalul Azam ${ }^{1 *}$, Sri Maryuni ${ }^{1}$, Fitri Indrawati ${ }^{1}$, Rudatin Windraswara ${ }^{1}$, and \\ Niruwan Turnbull ${ }^{2}$ \\ ${ }^{1}$ Department of Public Health, Faculty of Sports Science, Universitas Negeri Semarang, Semarang 50229 Indonesia \\ ${ }^{2}$ Faculty of Public Health, Mahasarakham University, Maha Sarakham 44150 Thailand
}

Corresponding author: Mahalul Azam

Email: mahalul.azam@mail.unnes.ac.id

\begin{abstract}
Diabetes mellitus (DM) is a well-known risk factor for tuberculosis (TB). Prevalence of TB among DM patients ranged from $1.7 \%$ to $36 \%$. Limited information has been reported regarding TB among DM patients in Indonesia. This casecontrol study aimed to investigate prevalence and related factors of pulmonary TB among DM patients in Dr. Kariadi General Hospital. Cases of pulmonary TB were defined by a positive acid-fast bacilli smear or molecular rapid test and thorax $x$-ray. Data were presented as frequency and percentage comparing the case and control group. Chi-square continued by Binary logistic regression analyses were done to determine the relationship between the parameters and TB status performed by the SPSS 16 . Prevalence of $8.02 \%$ or 72 patients were diagnosed as having pulmonary TB from 898 registered patients with DM. Of the 72 TB patients, 30 completed the data as case group, and 45 DM patients without TB determined as a control group. Comparison between the case and control group study found differences in household contact (63.3\% and $4.4 \%$, respectively), random plasma glucose $(76.7 \%$ and $33.3 \%)$, duration of DM (40\% and $71 \%$ ), and treatment compliance (30\% and 68.9\%). The final model in Binary logistic regression involved household contact, random plasma glucose level, and treatment compliance. The prevalence of pulmonary TB among DM patients in Dr. Kariadi General Hospital was 8.02\%. Risk factors that were associated with this occurrence were: household contact, high random plasma glucose level, and poor treatment compliance.
\end{abstract}

Keywords: Risk-factors, Pulmonary-Tuberculosis, Diabetes-Mellitus, Prevalence, Indonesia.

\section{INTRODUCTION}

Tuberculosis (TB) and Diabetes Mellitus (DM) are a global health problem nowadays. Reports from the World Health Organization (WHO) in 2017 show that there were 10.0 million deaths due to $\mathrm{TB}^{1}$. In the same year, there were 415 million cases and 5.0 million deaths due to $\mathrm{DM}^{2-5}$. DM patients have 3 times the risk of TB infection ${ }^{6}$ and are more susceptible because of their immune status ${ }^{7}$.

Previous reviews have concluded that the prevalence of TB among DM patients ranged from $1.7 \%$ to $36 \%$; similarly, DM prevalence among TB patients ranged from $1.9 \%$ to $45 \%$. The prevalence of pulmonary TB among DM patients globally is low, but it is relatively higher in the countries of Asia and Africa, ${ }^{8,9}$. Risk factors of pulmonar TB among DM found in the previous studies have been older age, male, lack of medical treatment, excessive weight, HIV infection, urban residence, tobacco smoking, sedentary lifestyle, poor glycemic control, and a family history of both $D M$ and $T^{5-9}$.

Both DM and TB are the burden of public health problems in Indonesia. it is estimated that between 2000 and 2030 Indonesia will have the highest number of DM cases ${ }^{7,10,11}$. Limited study has reported the prevalence of TB among DM patients in Indonesia. One study reported that the prevalence of TB among DM patients in Bandung, Indonesia was $3.66 \%$, and was related to age, sex, and house density ${ }^{12}$. The present study aimed to explore the prevalence and related factors of pulmonary TB among DM patients in Dr. Kariadi General Hospital, a national management center for TB and a referral hospital in Semarang, Central Java, Indonesia that administers patients from across Central Java and nationwide.

\section{METHODS}

The present study conducted a case-control study using secondary data as well as primary data. Secondary data were obtained from the medical records of the DM patients registry consecutively, either type I or type II DM, recorded at Dr. Kariadi General Hospital from January to July 2019. Primary data were obtained directly by interviewing subjects. The sample size was calculated based on Lemeshow ${ }^{13}$ formula of

$$
n 1=n 2=
$$

$\frac{\left\{\mathrm{Z} \alpha \sqrt{2 \mathrm{P}(1-\mathrm{P})}+\mathrm{Z} \beta \sqrt{\mathrm{P}_{1}\left(1-\mathrm{P}_{1}\right)+\mathrm{P}_{2}\left(1-\mathrm{P}_{2}\right\}^{2}}\right.}{\left(\mathrm{P}_{1}-\mathrm{P}_{2}\right)^{2}}$

After calculation and spare for the lost to follow up number, the minimum sample size for the case should be at least 24 subjects. We considered the 
equal number up to two times for the control group.

The study protocol was approved by the ethical committee of the Department of Public Health, Faculty of Sports Science, Universitas Negeri Semarang (No. 052 / KEPK / EC / 2019). Informed consent was obtained from all subjects. The case group consisted of DM patients with pulmonary TB determined by the diagnosis criterion, i.e. clinical manifestation either with a positive acid-fast bacilli smear or positive molecular rapid test and thorax x-ray. The control group consisted of DM patients that did not meet the pulmonary-TB diagnosis criteria, neither through clinical manifestation nor thorax $x$-ray.

This study observed the following characteristics of the subjects: age, sex, category of residence, level of household income and employment status. The following risk factors for pulmonary TB among DM patients were also observed: body mass index (BMI), family history of TB (household contact), level of random plasma glucose, duration of DM, type of DM therapy, treatment compliance, smoking history, and housing environment conditions. The residence was categorized as urban if it met the criteria of population density, percentage of agricultural households, and access to the urban facilities as regulated by the National Statistics Agency ${ }^{14}$. Treatment compliance was defined according to the Morisky Medication Adherence Scale- 8 as published elsewhere ${ }^{15}$. BMI was categorized as obese if it was > 25. The criteria of housing condition and house density was also defined by criteria published elsewhere ${ }^{16}$. The random plasma glucose level used, was that tested prior to the diagnosis of pulmonary TB, as taken from the medical records.

Since the data were categorical, they were presented by frequency and percentage and based on the results of the case group and control group. Chi-square analysis was performed to determine the relationship between the parameters and TB status. $P$ values of $<0.05$ were considered as statistically significant. Factors that had a $p$ value $<0.25$ were included in the multivariate analysis. The final model was analyzed using Binary logistic regression. All analyses were performed using the software SPSS 16.0 (IBM Corporation, NY, USA).

\section{RESULT}

A total of 898 patients were registered in the DM registry at Dr. Kariadi General Hospital during the study. A number of $72 \mathrm{DM}$ patients were diagnosed as having pulmonary $T B$, showing the prevalence of pulmonary TB among the DM patients in Dr. Kariadi General Hospital was $8.02 \%$. Of the 72 pulmonary TB patients, 8 patients died, 23 patients refused to be the subjects, and 11 patients didn't come to the hospital and could not be contacted. Finally, only 30 patients were interviewed and included in the analysis. The control group was selected consecutively from DM patients who were found free of pulmonary TB by the thorax x-ray until consisting of 45 patients considered the 1.5 times number of case group. (Recruitment of subjects in detail is explained in Figure 1).

In the group of DM with pulmonary TB $(n=30)$ the category of age was comparable to the group of DM without pulmonary TB $(n=45)$, i.e. most tended to be in the group of 15-64 years old with the proportion of 86.7 and 88.9 respectively (Table 1). Gender was also comparable between groups $(p=0.60)$, although the proportion of males in the pulmonary TB group was higher (53.3\%) than in the control group (44.4\%). The other characteristics, i.e. the employment status, category of residence, and level of household income, were comparable between the groups, as also shown in Table 1.

Table 2 showed the results of the Chi-Square tests for the risk factors. There were no differences for $\mathrm{BMI}$, type of DM therapy, smoking history, number and function of ventilations in the house, and housing density between DM patients with pulmonary TB and DM patients without pulmonary TB. The rest of the risk factors, i.e. household contact, random plasma glucose category, duration of $\mathrm{DM}$, and treatment compliance were related to the DM with pulmonary TB status. In the DM with pulmonary TB group, the proportion of household contact was higher $(63.3 \%$ ) than in the DM without pulmonary TB (4.4\%). In the category of random plasma glucose level higher than 200 $\mathrm{mg} / \mathrm{dL}$, the proportion in the DM with pulmonary TB group $(76.7 \%)$ was higher compared to the DM without pulmonary TB group $(33.3 \%)$. In the case group, the proportion of patients who did not comply with the treatment was higher (70\%) than the proportion in the control group (31.1\%). Strangely, the proportion with the duration of DM more than 5 years was lower $(40 \%)$ in the case group compared to the control group (71.1).

All the risk factors that were concluded to be related to the DM with pulmonary TB status by Chi-square test, as well as the risk factors with a $p$ value less than 0.25 , were hen included in the Binary logistic regression model. They were the existence of household contact, high random plasma glucose level, longer duration of DM, type of DM therapy, and poor treatment compliance. The final model of the regression is shown in Table 3 . The final model concluded that altogether household contact, high random plasma glucose level, duration of DM, and poor treatment compliance were associated with the status of $67.5 \%$ DM patients with pulmonary TB. The remaining $32.5 \%$ were influenced by other factors. The existence of household contact had the highest OR i.e. 63.29 (95\% Cl: 4.418-83.099), followed by high random plasma glucose i.e. 13.93 
(95\% Cl: 2.356-60.004), and poor treatment compliance, i.e. 4.27 (95\% Cl: 1.099-18.467). Duration of DM was involved in the final model; however, the $p$ value was not considered as a significant level $(p=0.079)$.

Table 1: Characteristics of Subjects

\begin{tabular}{|c|c|c|c|}
\hline Characteristics & DM with pulmonary TB & DM without pulmonary TB & $p$ value ${ }^{*}$ \\
\hline \multicolumn{4}{|l|}{ Age (years) } \\
\hline $15-64(n ; \%)$ & $26 ; 86.7$ & $40 ; 88.9$ & 1.00 \\
\hline$\geq 65(\mathrm{n} ; \%)$ & $4 ; 13.3$ & $5 ; 11.1$ & \\
\hline \multicolumn{4}{|l|}{ Gender } \\
\hline Male $(\mathrm{n} ; \%)$ & $16 ; 53.3$ & $20 ; 44.4$ & 0.60 \\
\hline Female $(n ; \%)$ & $14 ; 46.7$ & $25 ; 55.6$ & \\
\hline \multicolumn{4}{|l|}{ Employment Status } \\
\hline Employed(n;\%) & $18 ; 60.0$ & $27 ; 60.0$ & 1.00 \\
\hline Unemployed $(\mathrm{n} ; \%)$ & $12 ; 40.0$ & $18 ; 40.0$ & \\
\hline \multicolumn{4}{|l|}{ Category of residence } \\
\hline Urban (n;\%) & $16 ; 53.3$ & $26 ; 57.8$ & 0.89 \\
\hline Rural (n;\%) & $14 ; 46.7$ & $19 ; 42.2$ & \\
\hline \multicolumn{4}{|l|}{ Level of household income } \\
\hline Low (n;\%) & $20 ; 66.7$ & $26 ; 57.8$ & 0.59 \\
\hline Fair $(n ; \%)$ & $10 ; 33.3$ & $19 ; 42.2$ & \\
\hline
\end{tabular}

"Chi-square test

Table 2: Risk factors for pulmonary TB among DM patients

\begin{tabular}{|c|c|c|c|c|}
\hline Risk factors & DM- pulmonary & DM-non & $p$ value ${ }^{*}$ & OR $(95 \% \mathrm{Cl})$ \\
\hline BMI & & & \multirow{3}{*}{0.47} & \multirow{3}{*}{$\begin{array}{c}0.63 \\
(0.239-1.633)\end{array}$} \\
\hline Obese $(\mathrm{n} ; \%)$ & $10 ; 33.3$ & $20 ; 44.4$ & & \\
\hline Non-obese $(n ; \%)$ & $20 ; 66.7$ & $25 ; 55.6$ & & \\
\hline Household contact & & & \multirow{3}{*}{0.001} & \multirow{3}{*}{$\begin{array}{c}37.14 \\
(7.494-184.022)\end{array}$} \\
\hline Yes $(n ; \%)$ & $19 ; 63.3$ & $2 ; 4.4$ & & \\
\hline No $(n ; \%)$ & $11 ; 36.7$ & $43 ; 95.6$ & & \\
\hline Random plasma glucose & & & \multirow{3}{*}{0.001} & \multirow{3}{*}{$\begin{array}{c}6.57 \\
(2.302-18.756)\end{array}$} \\
\hline$\geq 200 \mathrm{mg} / \mathrm{dL}(\mathrm{n} ; \%)$ & $23 ; 76.7$ & $15 ; 33.3$ & & \\
\hline$<200 \mathrm{mg} / \mathrm{dL}(\mathrm{n} ; \%)$ & $7 ; 23.3$ & $30 ; 66.7$ & & \\
\hline Duration of DM & & & \multirow{3}{*}{0.02} & \multirow{3}{*}{$\begin{array}{c}3.69 \\
(1.394-9.781)\end{array}$} \\
\hline$\geq 5$ years $(n ; \%)$ & $12 ; 40.0$ & $32 ; 71.1$ & & \\
\hline$<5$ years $(\mathrm{n} ; \%)$ & $18 ; 60.0$ & $13 ; 28.9$ & & \\
\hline Type of DM therapy & & & \multirow{3}{*}{0.20} & \multirow{3}{*}{$\begin{array}{c}0.49 \\
(0.190-1.247)\end{array}$} \\
\hline OADs $(\mathrm{n} ; \%)$ & $12 ; 40.0$ & $26 ; 57.8$ & & \\
\hline Insulin (n;\%) & $18 ; 60.0$ & $19 ; 42.2$ & & \\
\hline Treatment compliance & & & \multirow{3}{*}{0.001} & \multirow{3}{*}{$\begin{array}{c}5.17 \\
(1.893-14.101)\end{array}$} \\
\hline No $(n ; \%)$ & $21 ; 70.0$ & $14 ; 31.1$ & & \\
\hline Yes $(n ; \%)$ & $9 ; 30.0$ & $31 ; 68.9$ & & \\
\hline Smoking history & & & \multirow{3}{*}{0.27} & \multirow{3}{*}{$\begin{array}{c}2.03 \\
(0.729-5.633)\end{array}$} \\
\hline Yes (n;\%) & $11 ; 36.7$ & $10 ; 22.2$ & & \\
\hline No (n;\%) & $19 ; 63.3$ & $35 ; 77.8$ & & \\
\hline Number and function of & & & \multirow{3}{*}{0.35} & \multirow{3}{*}{$\begin{array}{c}0.49 \\
(0.155-1.565)\end{array}$} \\
\hline Inadequate $(0-3)(n ; \%)$ & $5 ; 16.7$ & $13 ; 28.9$ & & \\
\hline Adequate $(>3)(n ; \%)$ & $25 ; 83.3$ & $32 ; 71.1$ & & \\
\hline Housing density & & & \multirow{3}{*}{0.93} & \multirow{3}{*}{$\begin{array}{c}1.56 \\
(0.292-8.278)\end{array}$} \\
\hline Dense (n;\%) & $3 ; 10.0$ & $3 ; 6.7$ & & \\
\hline Fair (n;\%) & $27 ; 90.0$ & $42 ; 93.3$ & & \\
\hline
\end{tabular}

BMI = Body Mass Index, OADs = Oral Antidiabetic Drugs

Table 3: Binary logistic regression

\begin{tabular}{lccc}
\hline \multicolumn{1}{c}{ Risk factors } & $\boldsymbol{B}$ & Adjusted OR & $\boldsymbol{P ~ v a l u e}^{*}$ \\
\hline Household contact & 6.678 & $63.29(4.418-83.099)$ & 0.000 \\
High random plasma glucose & 2.639 & $13.93(2.356-60.004)$ & 0.004 \\
Longer duration of DM & 1.303 & $3.68(0.817-18.562)$ & 0.079 \\
Poor treatment compliance & 1.453 & $4.27(1.099-18.467)$ & 0.043 \\
Constant & -4.223 & 0.015 & 0.000 \\
\hline
\end{tabular}

${ }^{*}$ Binary logistic regression, $\mathrm{R}^{2}=0.675$ (Nagelkerke) 


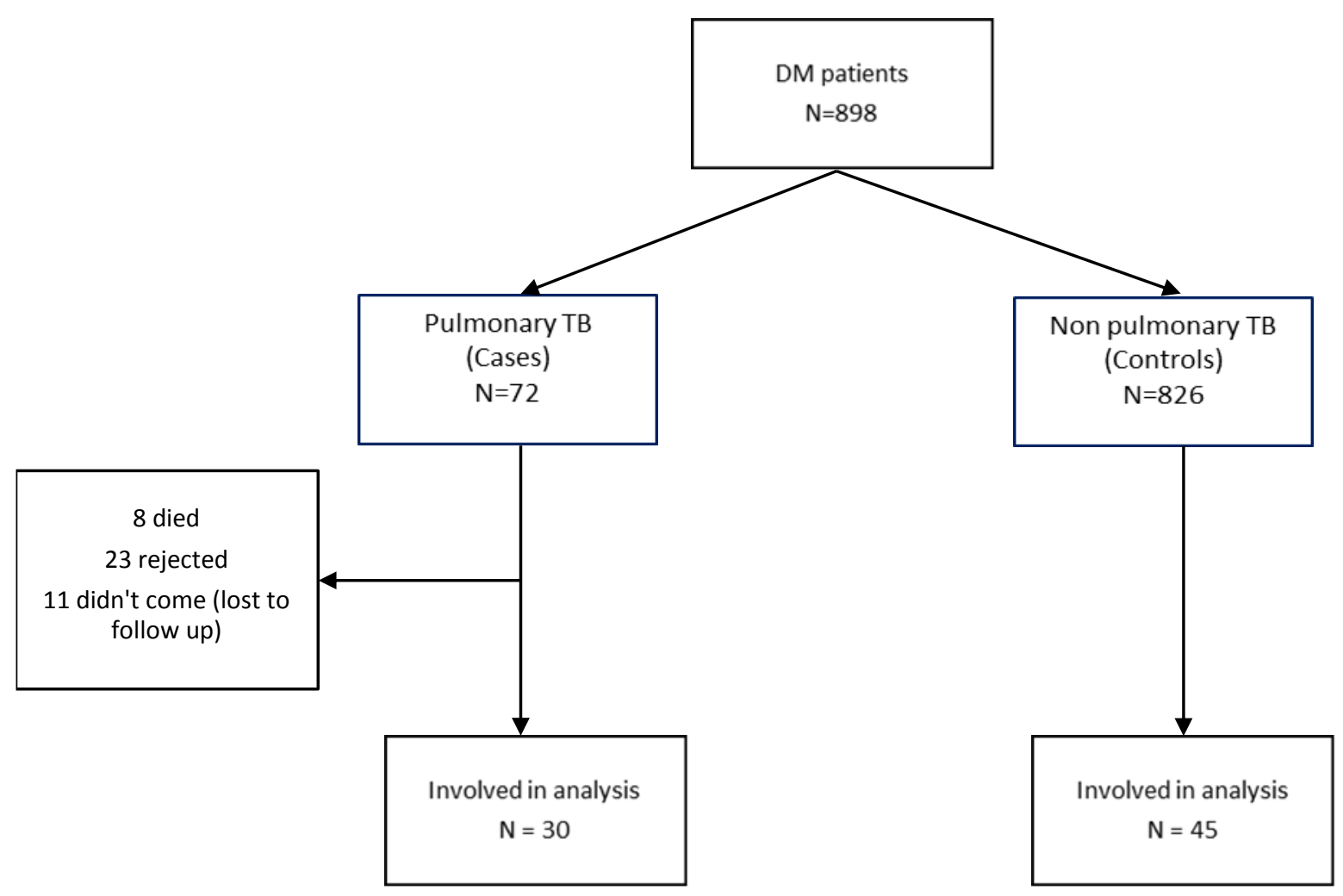

Figure 1. Recruitment of the subjects

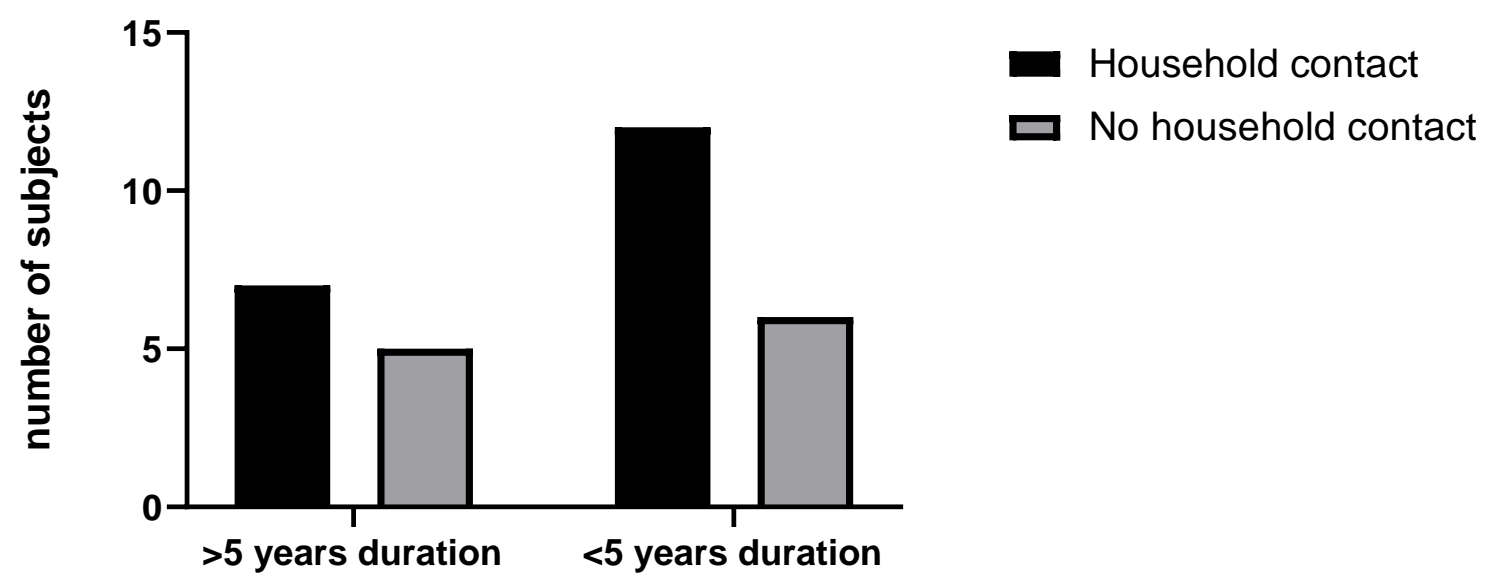

Figure 2. Duration of DM based on status of household contact

\section{DISCUSSION}

The current study adds to evidence of the prevalence of pulmonary TB patients among DM patients i.e. $8.02 \%$ in the setting of DM patients in Dr. Kariadi General Hospital, Semarang, Indonesia. This finding was in line with the previous study conducted in Ethiopia i.e. $6.2 \%{ }^{17}$ and was in the range as concluded in the review reports i.e. $1.7 \%$ to $36 \%$. The present study also adds evidence that risks factors, i.e. the existence of household contacts high random plasma glucose level, and poor treatment compliance altogether were associated with the pulmonary TB among DM patients. Household contact plays an important role in the transmission of TB infection in the population of DM patients as was also found in the present study. This finding was also reported in the previous studies conducted in Brazil and India ${ }^{18,19}$. A person without DM who has long-term contact is at high risk of being infected, with an estimated infection rate around $22 \%{ }^{20}$. Someone with active TB and without treatment can infect $10-15$ or more other people every year ${ }^{7}$. The present study showed the evidence that adjusted OR for the variable of household contact was 63.32 ( $95 \% \mathrm{Cl}=4.418-83.099)$ suggesting the 
risk for getting TB among DM patients with household contact was 63.29 times higher than without household contact.

Random plasma glucose also played a pivotal role in the occurrence of pulmonary TB among DM patients as reported in this study. This finding is following the common knowledge as reported previously which states that glucose control affects the incidence of TB in patients with $\mathrm{DM}^{7}$. Unfortunately, the present study failed to provide the HbA1C level data which would describe glucose control more precisely. Hyperglycemia in DM patients is a conducive medium for $M$. tuberculosis to grow, live, and multiply. There is an increase in glycerol and nitrogen levels in DM patients, which help the growth of bacilli as a cause of $\mathrm{TB}^{21-24}$. This study showed adjusted OR for random plasma glucose was 13.93 (95\% $\mathrm{Cl}=2.356-60.004)$, suggesting that risk for getting TB among DM patients with high random plasma glucose $(>200 \mathrm{mg} / \mathrm{dL})$ was 13.93 times higher compared to DM patients with low random plasma glucose $(<200 \mathrm{mg} / \mathrm{dL})$.

Treatment compliance also had association with the case of TB among DM patients in this study. Treatment compliance was reported as an independent risk factor for TB cases as well as its contribution to glucose control that finally has an impact on the occurrence of $\mathrm{TB}^{25,26}$. Adjusted $\mathrm{OR}$ for treatment compliance was 4.27 (95 \% $\mathrm{Cl}=1.099-18.467)$ concluded that DM patients who did not comply with the treatment have a risk of 4.27 times to get TB compared to compliant patients.

In the present study, the duration of DM was also associated with the occurrence of TB in DM patients. However, the analysis of this variable did not meet the significance consideration in the Binary logistic regression $(p=0.079)$, although the significance showed in Chi-square test $(p=$ 0.02 ). Unusual finding in this report showed that longer duration of DM (more than 5 years have a lower risk to get TB than the shorter (less than five years). The previous study concluded a common knowledge that the longer duration of DM tends to get TB than the shorter ${ }^{27}$. The immunity of the DM patient is more compromised, particularly for long duration DM as a result of micro- and macro-vascular complications as well as the treatment tolerance of the disease ${ }^{28}$. Indeed much is known about the duration of the DM implying the complication and severity of the diseases as well as the terminal outcome, either in the general complication or especially in the TB occurrence ${ }^{29-31}$. The present study did not provide evidence of a longer duration of DM as a risk factor for pulmonary TB, because of the interaction of household contact $(\mathrm{OR}=63.3)$ as the most influential factor. In this study, the proportion of shorter duration of DM was higher in the subjects with household contact group compared to the negative contact group (Figure 2). Considering a wide multi-center study with more sample size for further study may minimize the variable interactions.

\section{CONCLUSIONS}

The prevalence of pulmonary TB among DM patients in Dr. Kariadi General Hospital was 8.02\% suggesting adequate screening for pulmonary TB in DM patients management needs more attention. Risk factors that were associated with this occurrence were: the existence of household contact, high random plasma glucose level, and poor treatment compliance

\section{ACKNOWLEDGMENTS}

The authors acknowledge the Lembaga Penelitian dan Pengabdian Masyarakat (LPPM) Universitas Negeri Semarang for the financial support and the Dr. Kariadi General Hospital, Semarang, Indonesia for providing data and permission to meet patients.

\section{CONFLICT OF INTEREST}

The authors disclose that there is no conflict of interest regarding the research

\section{FUNDING SOURCES}

This study was supported by grant of DIPA PNBP UNNES 2019 No. 1603/UN37.3.1/TU/2019

\section{REFERENCES}

1. WHO. Global tuberculosis report 2017. Switzerland; 2017.

2. Singh K, Narayan KMV, Eggleston K. Economic Impact of Diabetes in South Asia: the Magnitude of the Problem. Curr Diab Rep. 2019;19(6).

3. Lange C, Abubakar I, Alffenaar JWC, Bothamley G, Caminero JA, Carvalho ACC, et al. Management of patients with multidrugresistant/ extensively drugresistant tuberculosis in Europe: A TBNET consensus statement. Eur Respir J. 2014;44(1):23-63.

4. Pande T, Huddart S, Xavier W, Kulavalli S, Chen T, Pai $M$, et al. Prevalence of diabetes mellitus amongst hospitalized tuberculosis patients at an Indian tertiary care center: A descriptive analysis. PLoS One. 2018;13(7):1-13.

5. Hoa NB, Phuc PD, Hien NT, Hoa VQ, Thuong $\mathrm{PH}$, Anh PT, et al. Prevalence and associated factors of diabetes mellitus among tuberculosis patients in Hanoi, Vietnam. BMC Infect Dis. 2018;18(1):1-9.

6. Da Costa JC, Oliveira O, Baía L, Gaio R, 
Correia-Neves M, Duarte R. Prevalence and factors associated with diabetes mellitus among tuberculosis patients: A nationwide cohort. Eur Respir J. 2016;48(1):264-8.

7. Restrepo BI. Diabetes and tuberculosis fact sheet. 2016;18(May):32-6.

8. Jeon $C Y$, Harries $A D$, Baker MA, Hart JE, Kapur A, Lönnroth K, et al. Bi-directional screening for tuberculosis and diabetes: A systematic review. Trop Med Int Heal. 2010;15(11):1300-14.

9. Workneh $\mathrm{MH}$, Bjune GA, Yimer SA. Prevalence and associated factors of tuberculosis and diabetes mellitus comorbidity: A systematic review1. Workneh MH, Bjune GA, Yimer SA. Prevalence and associated factors of tuberculosis and diabetes mellitus comorbidity: A systematic review. [cited 201. 2017;1-25.

10. Zimmet PZ, Magliano DJ, Herman WH, Shaw JE. Diabetes: a 21st century challenge. LANCET Diabetes Endocrinol. 2014;2(1):56-64.

11. Forouhi NG, Wareham NJ. Epidemiology of diabetes. Medicine (Abingdon, England: UK ed.). 2014;42(12):698-702.

12. Koesoemadinata RC, McAllister SM, Soetedjo NNM, Ratnaningsih DF, Ruslami R, Kerry $S$, et al. Latent TB infection and pulmonary TB disease among patients with diabetes mellitus in Bandung, Indonesia. Trans R Soc Trop Med Hyg. 2017;111(2):819.

13. Lemeshow S, Jr DWH, Klar J of M, Lwanga SK, Organization) (World Health. Adequacy of Sample Size in Health Studies. World Health Organization; 1990.

14. BADAN PUSAT STATISTIK. Peraturan Kepala Badan Pusat Statistik Nomor 37 Tahun 2010. 2nd ed. BPS; 2010.

15. Moon SJ, Lee WY, Hwang JS, Hong YP, Morisky DE. Accuracy of a screening tool for medication adherence: A systematic review and meta-analysis of the Morisky Medication Adherence Scale-8. PLoS One. 2017;12(11):1-18.

16. Low CT, Lai PC, Tse WSC, Tsui CK, Lee $\mathrm{H}$, Hui PK. Exploring tuberculosis by types of housing development. Soc Sci Med. 2013;87:77-83.

17. Amare H, Gelaw A, Anagaw B, Gelaw B. Smear positive pulmonary tuberculosis among diabetic patients at the Dessie referral hospital, Northeast Ethiopia. 2013;2-9.

18. Rajan J V., Ferrazoli L, Waldman EA, Simonsen V, Ferreira $P$, Telles MA, et al. Diabetes increases the risk of recentTransmission tuberculosis in household contacts in São Paulo, Brazil. Int J Tuberc Lung Dis. 2017;21(8):916-21.

19. Shivakumar SVBY, Chandrasekaran $P$, Kumar AMV, Paradkar M, Dhanasekaran K, Suryavarshini $\mathrm{N}$, et al. Diabetes and prediabetes among household contacts of tuberculosis patients in India: Is it time to screen them all? Int J Tuberc Lung Dis. 2018;22(6):686-94.

20. Ahmed N, Hasnain SE. Molecular epidemiology of tuberculosis in India : Moving forward with a systems biology approach. Tuberculosis. 2011;91(5):40713.

21. Laurentia Mihardja, Dina Bisara Lolong LG. The Prevalence of Diabetes Mellitus in Tuberculosis and the Treatment Problems. J Ekol Kesehat Vol 14 No 4, Desember 2015 350-358 Tuberc. 2015;14(4):350-8.

22. Dewi DPR, Putra IWGAE, Sawitri AAS, Duarsa DP. Risk factors of pulmonary tuberculosis among diabetes mellitus patients in Denpasar City. Public Heal Prev Med Arch. 2017;5(1):19.

23. Dooley KE, Chaisson RE. Tuberculosis and diabetes mellitus: convergence of two epidemics. Lancet Infect Dis. 2009;9(12):737-46.

24. Ahmed M, Omer I, Osman SMA, Abakur EHA. Association between Pulmonary Tuberculosis and Type 2 Diabetes in Sudanese Patients. J Mycobacteriology. 2017;97-101.

25. Singh SP, Singh SP, Kishan J, Kaur S, Ramana S. Association of tuberculosis and diabetes Mellitus: An analysis of 1000 consecutively admitted cases in a tertiary care hospital of North India. Pan Afr Med J. 2016;24:1-5.

26. Adisa R, Olajide O0, Fakeye TO. Social Support, Treatment Adherence and Outcome among Hypertensive and Type 2 Diabetes Patients in Ambulatory Care Settings in southwestern Nigeria. Ghana Med J. 2017;51(2):64-77.

27. Wu Z, Guo J, Huang Y, Cai E, Zhang X, Pan $Q$, et al. Diabetes mellitus in patients with pulmonary tuberculosis in an aging population in Shanghai, China: Prevalence, 
clinical characteristics and outcomes. J Diabetes Complications. 2016;30(2):23741.

28. Abera A, Ameya G. Pulmonary Tuberculosis and Associated Factors Among Diabetic Patients Attending Hawassa Adare Hospital, Southern Ethiopia. Open Microbiol J. 2018;12(1):333-42.

29. Syed Suleiman SA, Ishaq Aweis DM, Mohamed AJ, Razakmuttalif A, Moussa MAA. Role of diabetes in the prognosis and therapeutic outcome of tuberculosis. Int J
Endocrinol. 2012;2012.

30. Kundu D, Roy A, Mandal T, Bandyopadhyay U, Ghosh E, Ray D. Relation of microalbuminuria to glycosylated hemoglobin and duration of type 2 diabetes. Niger J Clin Pract. 2013;16(2):216-20.

31. Scardina GA, Citarrella R, Messina P. Diabetic microagiopathy of oral mucosa depends on disease duration and therapy. Med Sci Monit. 2017;23:5613-9. 